\title{
A Genome-Wide Screen for Spatially Restricted Expression Patterns Identifies Transcription Factors That Regulate Glial Development
}

\author{
Hui Fu, ${ }^{1,12}$ Jun Cai, ${ }^{5,6}$ Hans Clevers, ${ }^{7}$ Eva Fast, ${ }^{8}$ Susan Gray, ${ }^{4}$ Rachel Greenberg, ${ }^{9}$ Mukesh K. Jain, ${ }^{10}$ Qiufu Ma, ${ }^{1,2}$ \\ Mengsheng Qiu, ${ }^{6}$ David H. Rowitch, ${ }^{11}$ Christopher M. Taylor, ${ }^{1,3}$ and Charles D. Stiles ${ }^{1,3}$ \\ ${ }^{1}$ Department of Cancer Biology, Dana-Farber Cancer Institute, and Departments of ${ }^{2}$ Neurobiology and ${ }^{3}$ Microbiology and Molecular Genetics, Harvard \\ Medical School, Boston, Massachusetts 02115, ${ }^{4}$ Program in Molecular Medicine, University of Massachusetts Medical School, Worcester, Massachusetts \\ 01605, ${ }^{5}$ Department of Pediatrics, Kosair Children's Hospital Research Institute, and ${ }^{6}$ Department of Anatomical Sciences and Neurobiology, School of \\ Medicine, University of Louisville, Louisville, Kentucky 40202, ${ }^{7}$ Hubrecht Laboratory, 3584 CT Utrecht, The Netherlands, ${ }^{8}$ Department of Biology, Boston \\ University, Boston, Massachusetts 02215, ${ }^{9}$ Department of Biological Sciences, Columbia College, Columbia University, New York, New York $10027,{ }^{10} \mathrm{Case}$ \\ Cardiovascular Research Institute, Case Western Reserve University School of Medicine, Cleveland, Ohio 44106, ${ }^{11}$ Departments of Pediatrics and \\ Neurological Surgery and the Institute for Regeneration Medicine, University of California, San Francisco, San Francisco, California 94143 , and \\ ${ }^{12}$ Department of Physiology, Basic Medical College of Nanchang University, Nanchang, Jiangxi 330006, China
}

Forward genetic screens in genetically accessible invertebrate organisms such as Drosophila melanogaster have shed light on transcription factors that specify formation of neurons in the vertebrate CNS. However, invertebrate models have, to date, been uninformative with respect to genes that specify formation of the vertebrate glial lineages. All recent insights into specification of vertebrate glia have come via monitoring the spatial and temporal expression patterns of individual transcription factors during development. In studies described here, we have taken this approach to the genome scale with an in silico screen of the Mahoney pictorial atlas of transcription factor expression in the developing CNS. From the population of 1445 known or probable transcription factors encoded in the mouse genome, we identify 12 novel transcription factors that are expressed in glial lineage progenitor cells. Entry-level screens for biological function establish one of these transcription factors, Klf15, as sufficient for genesis of precocious GFAP-positive astrocytes in spinal cord explants. Another transcription factor, Tcf4, plays an important role in maturation of oligodendrocyte progenitors.

\section{Introduction}

The spatial and temporal expression patterns of transcription factors during development shed light on the specification of vertebrate glia. For example, the basic helix-loop-helix (bHLH) transcription factors Olig1 and Olig2, which promote formation of oligodendrocytes, were identified via their initial expression in the pMN (motor neuron progenitor) domain of the embryonic spinal cord (Lu et al., 2000; Zhou et al., 2000), which gives rise to spinal cord oligodendrocytes (Lu et al., 2002; Takebayashi et al., 2002; Zhou and Anderson, 2002). Olig2 knock-out mice fail to develop oligodendrocytes and motor neurons in the spinal cord, whereas Olig1 knock-out mice show slight delays in oligodendrocyte maturation as well as impaired remyelination (Arnett et al., 2004; Xin et al., 2005). In a similar vein, gliogenic functions of the Scl and Nfia transcription factors were initially suggested by their develop-

Received Jan. 12, 2009; revised Aug. 7, 2009; accepted Aug. 7, 2009.

This research was supported by National Institutes of Health Grant NS059893 and National Natural Science Foundation of China Grant N030860131. We thank Dr. William Stallcup for NG2 antibody and Dr. David Anderson for Sox10 antibody. We also thank Xuemei Hu for technical support.

Correspondence should be addressed to Charles D. Stiles, Department of Cancer Biology, Dana-Farber Cancer Institute, Harvard Medical School, Boston, MA 02115.E-mail: Charles_stiles@dfci.harvard.edu.

DOI:10.1523/JNEUROSCI.0160-09.2009

Copyright $\odot 2009$ Society for Neuroscience $\quad$ 0270-6474/09/2911399-10\$15.00/0 mentally regulated expression in neural progenitors that give rise to astrocytes (Muroyama et al., 2005; Deneen et al., 2006). Scl specifies formation of $\mathrm{V} 2 \mathrm{~b}$ interneurons and astrocytes in a regionally restricted area [p2 (progenitor domain 2)] of the ventral spinal cord. Nfia is expressed in Olig2-positive $\left(\mathrm{Olig} 2^{+}\right.$) cells at the onset of gliogenesis in the embryonic spinal cord. Both Scl and Nfia exhibit antagonistic interactions with Olig2.

In studies described here, we have taken the spatial and temporal expression pattern approach to the genome scale with an in silico screen of the Mahoney pictorial atlas of transcription factor expression in the developing CNS (Gray et al., 2004). From an entry-level list of $>1400$ candidates, we have identified 87 transcription factors that are expressed at early times in the germinal zone of developing spinal cord, 12 of which are novel transcription factors that (1) show sustained expression in spinal cord white matter and (2) have not hitherto been linked to glial development. We identify three novel transcription factors related to the astrocyte lineage and nine transcription factors related to the oligodendrocyte lineage. Entry-level screens for biological function establish one of the astrocyte-related transcription factors, Klf15, as sufficient for genesis of precocious GFAP-positive astrocytes in spinal cord explants, whereas the oligodendrocyte-related transcription factor Tcf4 plays an important role in maturation of oligodendrocyte progenitors. 
A E13.5
B

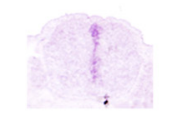

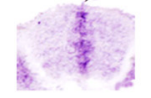
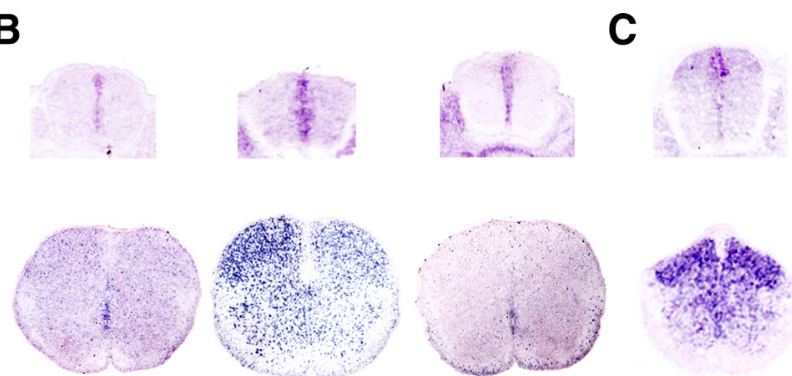

Klf15

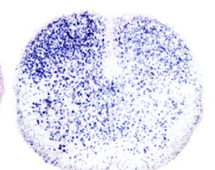

Egr4

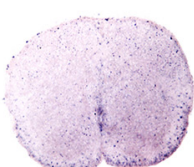

Erf

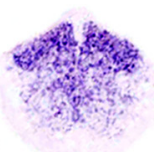

Nsd1

Figure 1. An in silico screen for transcription factors that direct formation of glia. $\boldsymbol{A}$, Grayscale drawings are schematic views of glial progenitors in the developing spinal cord. At E13.5, glial progenitors are sequestered within the ventricular zone. At P0, these progenitors have migrated throughout the gray and white matter of the spinal cord. $\boldsymbol{B}$, Color micrographs: three representative examples of transcription factors from the Mahoney database that show spatial/temporal expression patterns consistent with a role in specification/maturation of glia. C, Example of a transcription factor with a predominantly gray matter expression pattern at P0. For details, see Results.

\section{Materials and Methods}

Animals. Timed-pregnancy CD-1 mice were ordered from Charles River. The genotypes of Tcf4 $4^{-1-}, N k \times 6.1^{-1-}, N k \times 2.2^{-1-}$, Sox $10^{-1-}, \mathrm{Klfl}^{-1-}$,

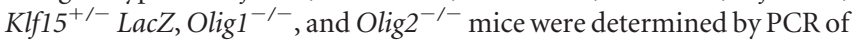
the genomic DNA, which has been reported previously (Korinek et al., 1998; Qi et al., 2001; Lu et al., 2002; Stolt et al., 2002; Liu et al., 2003; Fisch et al., 2007; Gray et al., 2007).

In situ hybridization and immunostaining. In situ hybridization (ISH) and immunofluorescent (IF) procedures were performed as described previously (Fu et al., 2002; Gray et al., 2004). Double staining was performed by first conducting ISH followed by IF. ISH images were pseudocolored using Adobe Photoshop (Adobe Systems) and then combined with IF images to obtain double-staining images. Antibodies used in this study include the following: anti-Tcf4 (1:200; Upstate), NG2 (1:200; Dr. William Stallcup, Burnham Institute for Medical Research, Cancer Research Center, La Jolla, CA), Sox10 (1:10; Dr. David Anderson, California Institute of Technology, Pasadena, CA), Olig1 [1:500 (Arnett et al., 2004)], Olig2 [1:10,000 (Arnett et al., 2004)], MBP (1:200; Millipore Bioscience Research Reagents), CNPase (1:100; Sigma), GFAP (1:200; Sigma), $\beta$-catenin (1:200; BD Biosciences), Ki67 (1:200; Novocastra), Hmgb1 (1:100; Abcam), Hmgb2 (1:500; Abcam), Erf (1:200; Abcam), Rxra (1:100; R \& D Systems), and Tcf12 (1:50; Novus Biologicals).

Mixed glia culture. The cortices of neonatal [postnatal day 1 (P1) to P2] rat pups were used for mixed glia culture (McCarthy and de Vellis, 1980). Cortices were physically dissociated and plated on poly-L-ornithinecoated coverslips, grown in vitro for $13 \mathrm{~d}$ (DMEM/F-12, 10\% FBS, and penicillin/streptomycin). Coverslips were fixed in $4 \%$ paraformaldehyde for immunostaining.

Spinal cord explant culture and electroporation. The spinal cords of embryonic day 11.5 (E11.5) mouse embryos were dissected out, and only the cervical region was used for tissue culture. The cervical spinal cord was transferred onto $0.8 \mu \mathrm{M}$ nitrocellulose membrane (Millipore Corporation) with the ventricular side facing up. After $2 \mathrm{~h}$ in culture media (DMEM, 5\% FBS, and penicillin/streptomycin) in $37^{\circ} \mathrm{C}$ incubator, plasmids were electroporated onto the ventricular side of the spinal cord explant culture. After $6 \mathrm{~d}$ in culture, the explants were fixed and sectioned for GFAP immunostaining.

Full-length mouse Olig2, Klf15 (Open Biosystems), and Scl (from Dr. David Rowitch, Departments of Pediatrics and Neurological Surgery, University of California, San Francisco, CA) cDNA were subcloned into the pIRES2-acGFP1 (BD Biosciences) expression vector for electroporation.

\section{Results}

\section{An in silico screen for transcription factors that direct formation of glia}

The Mahoney atlas was generated by using computer algorithms to search for protein sequences encoded in the existing public and private databases (Sonnhammer et al., 1998; Matys et al., 2003; Thomas et al., 2003; Wheeler et al., 2004). Open reading frames were classified as transcription factors only if their predicted protein sequence included a Protein Families Database-defined DNA binding domain. By this definition, a total of 1445 known or probable transcription factors were shown to be encoded in the mouse genome. Colorimetric in situ hybridization was used to map the expression of $>1000$ of these transcription factors and transcription factor-coregulator genes in the brains of developing mice (Gray et al., 2004).

We screened this atlas for transcription factors that may play a role in the regulation of glial development. We chose to focus on expression in the spinal cord for our in silico screen on the basis of its relatively simple anatomical structure. Our entry-level screen was for transcription factors that are expressed within the germinal zone of the spinal cord at a time (E13.5) that coincides approximately with the neural/glial switch (Fig. 1). A comprehensive list of 87 transcription factors that showed germinal zone-restricted expression at E13.5 is provided in Table 1.

As a secondary screen, we monitored the 87 transcription factors listed in Table 1 for sustained expression at later times in the white matter of the spinal cord. By P0, the majority of the 87 transcription factors detected at E13.5 were no longer expressed or were expressed exclusively in gray matter (Fig. 1C). Transcription factors expressed exclusively in gray matter were discounted. However, 20 members of the initial set of 87 were still expressed at $\mathrm{P} 0$ in white matter exclusively or in white matter and gray matter together. Some representative images from the P0 screen are shown in Figure 1, and a comprehensive list of the P0 transcription factors is included in Table 2. It should be noted that all of the transcription factors in this subset are also expressed in neurons. Furthermore, the design of this screen was geared toward identification of transcription factors expressed in glial progenitors. As such, it is possible that some of these transcription factors are involved in maintaining an immature phenotype rather than promoting terminal differentiation. Similarly, the experimental design would naturally exclude transcription factors that are expressed exclusively in gray matter astrocytes.

Note that the E13.5 and P0 inventory of spatially restricted transcription factors in Tables 1 and 2 includes 12 transcription factors that have been linked previously to the formation of glia, including Olig1, Olig2, Scl, Nfia, and Sox9. The presence of these factors serves in part to validate our screening strategy. In addition, Table 2 lists 12 novel transcription factors that show sustained expression in white matter at P0 and have not been associated previously with glial development. These 12 transcription factors were singled out for additional study. 
Table 1. Transcription factors with germinal zone-restricted expression at E13.5

\begin{tabular}{|c|c|c|c|c|c|}
\hline Gene name & Family & LocusID & Gene name & Family & LocusID \\
\hline Arntl & bHLH & 11865 & Hmgb1 & HMG & 15289 \\
\hline Neurod4 & bHLH & 11923 & Sox14 & HMG & 20669 \\
\hline $\operatorname{Hes} 5^{a}$ & bHLH & 15208 & $\mathrm{Bbx}$ & HMG & 70508 \\
\hline $\operatorname{ld} 2^{a}$ & bHLH & 15902 & Irx1 & Homeobox & 16371 \\
\hline $\mathrm{Id} 1^{a}$ & bHLH & 15901 & Irx3 & Homeobox & 16373 \\
\hline $\mathrm{Id} 3^{a}$ & bHLH & 15903 & Lhx2 & Homeobox & 16870 \\
\hline Srebf1 & bHLH & 20787 & Ihx4 & Homeobox & 16872 \\
\hline Tff12 & bHLH & 21406 & LHP/Lhx8 & Homeobox & 16875 \\
\hline Tcf4 & bHLH & 21413 & $\mathrm{Nkx} 2.2^{a}$ & Homeobox & 18088 \\
\hline E47 & bHLH & 21423 & Nkx6. $1^{a}$ & Homeobox & 18096 \\
\hline Tfeb & bHLH & 21425 & $0 \mathrm{tx} 2$ & Homeobox & 18424 \\
\hline Olig2 $2^{a}$ & bHLH & 50913 & Рax3 & Homeobox & 18505 \\
\hline $0 \operatorname{lig} 1^{a}$ & bHLH & 50914 & Pax7 & Homeobox & 18509 \\
\hline Mxd3 & bHLH & 17121 & $\operatorname{Six} 5$ & Homeobox & 20475 \\
\hline Smarcc1 & Bromo & 20588 & Tgif2 & Homeobox & 228839 \\
\hline Brd7 & Bromo & 26992 & Hoxd3 & Homeobox & 15434 \\
\hline Crebl1 & bZIP & 12915 & Pknox1 & Homeobox & 18771 \\
\hline Atf4 & bZIP & 11911 & Pdlim4 & Lim & 30794 \\
\hline $\mathrm{Tsc} 22 \mathrm{~d} 4$ & bZIP & 78829 & Csrp2 & Lim & 13008 \\
\hline Cited4 & Cited & 56222 & Prickle3 & Lim & 54630 \\
\hline $\mathrm{Nfia}^{a}$ & CTF/NF-I & 18027 & Rest & Myb & 104383 \\
\hline $\mathrm{Nfib}^{a}$ & CTF/NF-I & 18028 & $\mathrm{Btf3}$ & $\mathrm{NaC}$ & 218490 \\
\hline Nfix & CTF/NF-I & 18032 & Rxra & Nucrec & 20181 \\
\hline $\mathrm{E} 2 \mathrm{f} 1$ & E2f & 13555 & Rxrb & Nucrec & 20182 \\
\hline Tfdp1 & E2f & 21781 & $\mathrm{Nr} 1 \mathrm{~h} 2$ & Nucrec & 22260 \\
\hline E2f6 & E2f & 50496 & Nr2e1 & Nucrec & 21907 \\
\hline $\mathrm{E} 2 \mathrm{f} 2$ & E2f & 242705 & Trp53 & p53 & 22059 \\
\hline E2f3 & E2f & 13557 & Per2 & PAS & 18627 \\
\hline E2f5 & E2f & 13559 & $R f x 3$ & RFX & 19726 \\
\hline Erf & ETS & 13875 & $\mathrm{Rf} \times 4$ & RFX & 71137 \\
\hline Fox04 & Forkhead & 54601 & Nfatc3 & Rhd & 18021 \\
\hline FoxM1 & Forkhead & 14235 & Tbpl1 & TBP & 237336 \\
\hline FoxJ1 & Forkhead & 15223 & Tead2/KIf3 & TEA & 21677 \\
\hline FoxK1 & Forkhead & 17425 & Ciao1 & WD40 & 26371 \\
\hline Gtf2i & GTF2I & 14886 & Sall2 & Zinc & 50524 \\
\hline $\mathrm{Hmg20b}$ & HMG & 15353 & Egr4 & $\mathrm{ZNC} 2 \mathrm{H} 2$ & 13656 \\
\hline Sox $10^{a}$ & HMG & 20665 & Sp1 & $\mathrm{ZNC} 2 \mathrm{H} 2$ & 20683 \\
\hline Sox2 & HMG & 20674 & Zfp26 & $\mathrm{ZNC2H} 2$ & 22688 \\
\hline Sox $9^{a}$ & HMG & 20682 & KIf15 & $\mathrm{ZNC} 2 \mathrm{H} 2$ & 66277 \\
\hline Tf3 & HMG & 21415 & Zkscan3 & $\mathrm{ZNC2H} 2$ & 72739 \\
\hline Tcf7l2 & HMG & 21416 & Nsd1 & $\mathrm{ZnPhD}$ & 18193 \\
\hline Smarce1 & HMG & 57376 & Phf21a & ZN PHD & 192285 \\
\hline Hmgb2 & HMG & 97165 & Mid1 & ZN RING B BOX & 17318 \\
\hline Sox21 & HMG & 223227 & & & \\
\hline
\end{tabular}

${ }^{a} G$ enes known previously to be regulators for development of glia.

\section{Segregation into oligodendrocyte- and astrocyte-related subgroups}

The CNS white matter contains both oligodendrocytes and GFAP-positive fibrous astrocytes (Privat and Rataboul, 1986). To resolve the cell types marked by novel transcription factors in our P0 "short list," we performed in situ hybridization for the various transcription factors together with immunofluorescence with antibodies to Olig1 or Olig2, a pair of bHLH transcription factors that show $>95 \%$ overlap in expression (and thus were treated as interchangeable for our purposes here) and are restricted to the nuclei of oligodendrocytes and oligodendrocyte progenitors in the P0 spinal cord (Lu et al., 2000; Takebayashi et al., 2000; Zhou et al., 2000). Transcription factors that were mainly precluded from Olig2-positive cells were considered to be astrocyte related (Fig. $2 A, B$ ). Transcription factors that primarily colocalized with Olig2 were considered to be in an oligodendrocyte-related group (Fig. $2 A, B$ ). To see whether P0 expression patterns reflect adult patterning, we performed expression analysis on Tcf4 and Klf15
Table 2. Transcription factors with glial expression pattern at $\mathbf{P O}$

\begin{tabular}{|c|c|c|}
\hline Gene name & Family & LocusID \\
\hline $0 \operatorname{lig} 2^{a}$ & bHLH & 50913 \\
\hline $0 \operatorname{lig} 1^{a}$ & bHLH & 50914 \\
\hline Klf15 & $\mathrm{ZNC} 2 \mathrm{H} 2$ & 66277 \\
\hline Rxra & Nucrec & 20181 \\
\hline Rxrb & Nucrec & 20182 \\
\hline $\operatorname{Nkx} 2.2^{a}$ & Homeobox & 18088 \\
\hline Tcf7l2 & HMG & 21416 \\
\hline Hmgb2 & HMG & 97165 \\
\hline $\operatorname{Hes} 5^{a}$ & bHLH & 15208 \\
\hline $\operatorname{ld} 2^{a}$ & bHLH & 15902 \\
\hline $\operatorname{ld} 3^{a}$ & bHLH & 15903 \\
\hline Sox $10^{a}$ & HMG & 20665 \\
\hline Sox $9^{a}$ & HMG & 20682 \\
\hline $\mathrm{E} 2 \mathrm{f2}$ & E2f & 242705 \\
\hline Erf & ETS & 13875 \\
\hline E2f1 & E2f & 13555 \\
\hline Six 5 & Homeobox & 20475 \\
\hline Hmgb1 & HMG & 15289 \\
\hline Egr4 & $\mathrm{ZNC} 2 \mathrm{H} 2$ & 13656 \\
\hline Tcf12 & bHLH & 21406 \\
\hline
\end{tabular}

(supplemental Fig. 1, available at www.jneurosci.org as supplemental material). In the postnatal spinal cord, Tcf4 expression is exclusive to oligodendrocyte lineage cells and decreases as myelination proceeds, whereas Klf15 is mainly expressed in the astrocyte lineage. In the brain, Tcf4 is also expressed in neurons, especially in the thalamus. Overall, a group of nine transcription factors are oligodendrocyte related by this criterion and three are astrocyte related.

Our classification of the astrocyte-related transcription factors was further validated by examining the spinal cords of Olig2 knock-out mice and by misexpression studies. Targeted disruption of Olig2 leads to complete ablation of the oligodendrocyte lineage throughout the spinal cord, whereas formation of astrocytes is unperturbed ( $\mathrm{Lu}$ et al., 2002). All three of the astrocyte-related transcription factors are expressed equally well in wild-type and Olig2 knock-out spinal cords. Representative in situ images of Hmgb2 (astrocyte group) and Tcf4 (oligodendrocyte group) in the spinal cords of wild-type and Olig2 knock-out mice are shown in Figure $3 A$ (supplemental Fig. 2, available at www. jneurosci.org as supplemental material). With the exception of Tcf4, no striking differences were seen in the oligodendrocyterelated group of transcription factors within the white matter (supplemental Fig. 3, available at www.jneurosci.org as supplemental material). Because Tcf4 is the only transcription factor with $100 \%$ overlap with Olig2 and the other oligodendrocyterelated transcription factors are also expressed in neurons, this result is not surprising. Tcf12 and Rxra expression is lost in the motor neuron region, consistent with previous reports of motor neuron loss in the Olig2 knock-out mice.

\section{Functional analysis of an astrocyte-related transcription factor}

From commercial sources, we were able to obtain full-length cDNA for two of the transcription factors in the astrocyte-related group. For comparative purposes, we also obtained full-length cDNA clones corresponding to two of the nine novel transcription factors in the oligodendrocyte-related group. After validating the nucleic acid sequences, these full-length cDNAs were placed into expression vectors and electroporated into E11.5 "open book" mouse spinal cord explant cultures as described in Materials and 
Methods. At day 6 after electroporation, the explant cultures were fixed, sectioned, and immunostained for GFAP. As a positive control for the open book cultures, we used Scl, a bHLH transcription factor that has been shown previously to be both necessary and sufficient to promote formation of astrocytes in a regionally restricted domain of the ventral spinal cord (Muroyama et al., 2005). As a negative control, we used the oligodendrocyte-specific bHLH transcription factor Olig2, which specifies formation of oligodendrocytes.

As shown in Figure $3 B$, Scl and Klf15 promoted formation of precocious GFAPpositive cells, whereas Hmgb2 did not (data not shown). In contrast, neither Olig2 nor the two novel transcription factors from the oligodendrocyte-related group (Tcf4, Tcf12) displayed this activity (Fig. 3B, and data not shown). Physiologic relevance of Klf15 function in these spinal explant cultures was validated using a Klf15 $\beta$-galactosidase knock-in mouse (Fisch et al., 2007) for fate mapping. As indicated in Figure $3 C$, we observed excellent overlap between $\beta$-galactosidase ( $\beta$-gal) expression and GFAP staining $(>60 \%)$ and poor overlap with $\beta$-gal expression and Olig1 staining $(<15 \%)$ in the postnatal spinal cord (quantification not shown). As a technical aside, our spinal cord explants routinely express GFAP-positive astrocytes at day 7 in vitro. Because explant cultures are harvested one day earlier (day 6 in vitro), we were unable to determine whether overexpression of oligodendrocyte-related transcription factors results in repression of GFAP expression. Overexpression of the oligodendrocyte transcription factors (even control Olig2) did not stimulate expression of late-stage oligodendrocyte markers in spinal cord explants, suggesting that additional transcription factors [e.g., Nkx2.2 (Zhou et al., 2001)] are necessary for oligodendrocyte progenitors to progress to the MBP-expressing developmental stage.

\section{Tcf4 is an oligodendrocyte-related} transcription factor

We chose to pursue Tcf4 for detailed study from our collection of potential pro-oligodendrocyte lineage genes (1) because it was the only transcription factor that showed $100 \%$ overlap with Olig2, (2) because it was the only oligodendrocyte transcription factor whose expression was disrupted in the Olig2 knock-out spinal cord, and (3) because of its provocative relationship to the $\mathrm{Wnt} / \beta$-catenin signaling pathway. A functional overlap between Tcf4 and Olig2 suggested by the phenotype of Olig2 knock-out spinal cords (Fig. 3A) was further resolved with a series of knock-out mouse models that feature a moderate-to-severe impact on myelin development. The list includes Nkx6.1 and Sox10 (severe phenotype) and Olig1 and Nkx2.2 (moderate phenotype) (Qi et al., 2001; Lu et al., 2002;
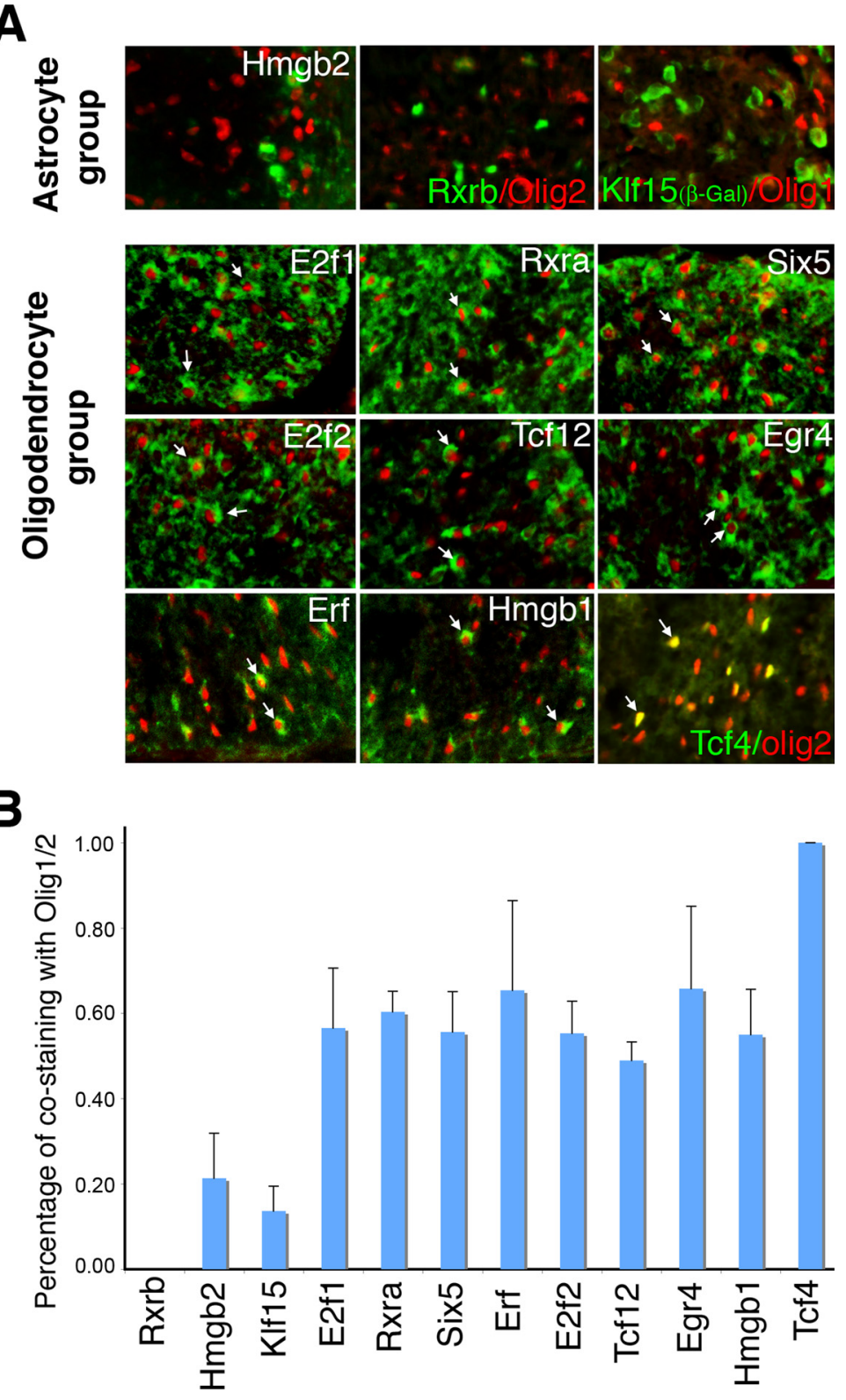

Figure 2. Segregation of glia-related transcription factors into an astrocyte group and oligodendrocyte group. $A$, Expression assays in PO spinal cords. Oligodendrocytes are imaged by immunofluorescence with antibodies to 0lig2 or (in the case of KIf15) Quantification of double-stained cells, presented as percentage overlap with 0lig1/2. Klf15 was double stained with Olig1. All other transcription factors were double stained with Olig2. Error bars indicate SD ( $n$ values: Rxrb, 3; Hmgb2, 14; KIf15, 7 ; E2f1, 7; Rxra, 5; Six5, 6; Erf, 9; E2f2, 6; Tcf12, 3; Egr4, 5; Hmgb1, 12; Tcf4, 9).

Stolt et al., 2002; Takebayashi et al., 2002; Zhou and Anderson, 2002; Liu et al., 2003). As shown in Figure 4, Tcf4 expression is ablated or severely delayed in all four of these hypomyelination mouse models. Olig1 knock-out mice are viable and some Nkx2.2 animals survive to P7. Low levels of Tcf4 expression were seen at P5 in Olig1 and Nkx2.2 knock-out animals (data not shown).

Physiologic relevance of Tcf 4 ablation in the various hypomyelination models is suggested by Tcf 4 immunostaining experiments at intervals ranging from E18.5 to adult life (Fig. 5). As indicated in Figure 2, all Tcf4-positive cells express the oligodendrocyte lineage marker Olig2. At E18.5, Tcf4 protein is detectable but only within a minor subset of cells in the ventral spinal cord 
A
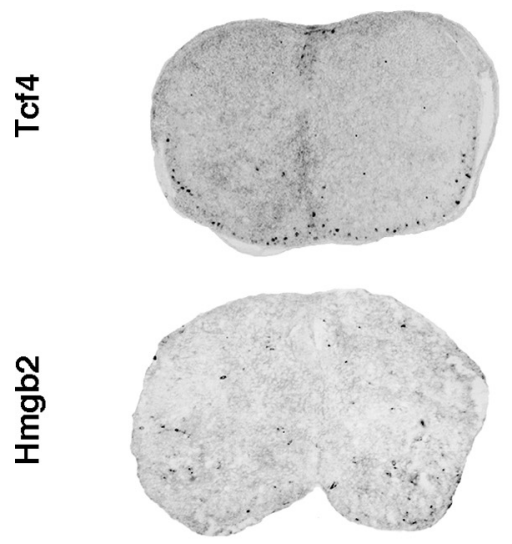

B
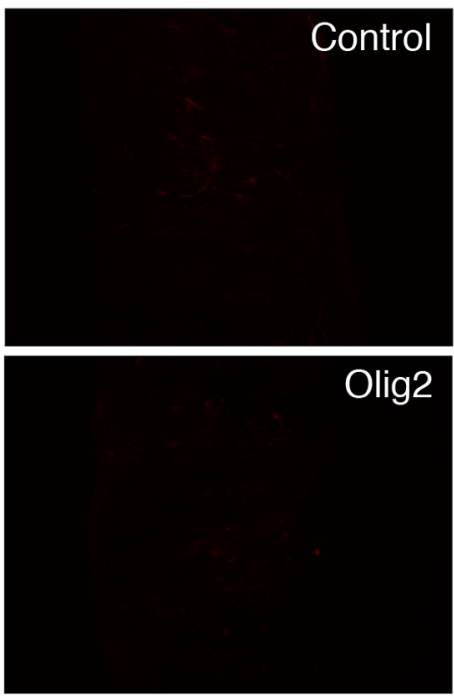

C

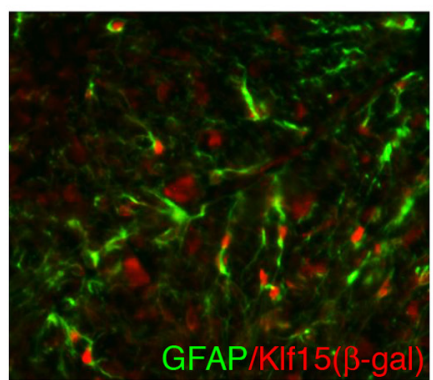

Figure 3. Analysis of astrocyte-related transcription factors. A, At E18.5, Hmgb2 has very similar expression in 0lig2 knock-0ut (KO) spinal cords and in wild-type (Wt) littermates, whereas Tcf4 expression is ablated in 0lig2 knock-out spinal cords. Tcf4 is used as a negative control. $\boldsymbol{B}$, KIf15, an astrocyte group gene, induces ectopic GFAP expression in mouse spinal cord explant cultures. No GFAP expression is found in Olig2 or empty vector control transfected spinal cord explants. GFAP expression is also observed when the astrocyte-promoting transcription factor $S c /$ is electroporated into the spinal cord. C, Double immunostaining showed colocalization of GFAP and KIf15 ( $\beta$-gal) in P14 spinal cord of Klf15 heterozygotes (with $\beta$-gal knock-in at the KIf15 locus).

The disconnect between mRNA and protein expression may reflect some level of translational or posttranslational regulation of Tcf4.

\section{Tcf4 marks postmitotic/premyelinating oligodendrocytes}

The relationship between expression of the Tcf4 and Olig2 proteins is not symmetric. Although all Tcf4-positive cells express Olig2, many Olig2-positive cells do not express Tcf4. To identify the subset of oligodendrocyte progenitors marked by Olig 2 and Tcf4, we turned to mixed glial cultures from neonatal rat cortex. Oligodendrocyte progenitors in mixed glial cultures differentiate into myelin-positive oligodendrocytes over a 2 week period of time. Differentiation is asynchronous so that, at any given time, a mixed population of immature, partially mature, and mature oligodendrocytes can be observed (McCarthy and de Vellis, 1980). A cellular "deletion map" of maturational stages in these cultures can be obtained with a set of marker proteins that are expressed at timed intervals as shown (Fig. 6A).

As shown in Figure $6 B$, Tcf4 protein is expressed in a subset of the cells with the sustained early markers (Olig1, Olig2 or Sox10). Tcf4 is also expressed in a subset of cells marked by proteins that are expressed at early (NG2) or late (MBP) stages of the maturational process. However, the marker most closely linked with Tcf4 ( $~ 90 \%$ coexpression) is CNPase, a protein expressed as oligodendrocytes exit the cell cycle for terminal differentiation (Barradas et al., 1995). The linkage between Tcf4 expression and cell cycle exit is further confirmed by double immunostaining with antibodies to Ki67, a marker for dividing cells. As indicated (Fig. 6C), there is no overlap between Tcf4 and Ki67 at any stage of development, showing that Tcf4 is expressed only in postmitotic cells.

\section{Tcf4 expression is required for} maturation of oligodendrocyte progenitors but is dispensable for their initial specification

Ablation of white matter by targeted disruption of pro-myelin transcription factors leads to loss of Tcf4-positive cells

(Fig. 5, compare E18.5 Tcf4 image with E18.5 Olig2). Between P0 and P14, Tcf4-positive cells become more abundant, and they are dispersed throughout the gray and white matter of the spinal cord. However, in adult mice, Tcf4-positive cells can no longer be detected in white matter of the spinal cord. Likewise, Tcf4 protein is not expressed in adult corpus callosum (data not shown). Note that Tcf4 protein expression does not strictly overlap the expression of Tcf4 mRNA (Fig. 5, compare weak Tcf4 protein expression at E18.5 with robust mRNA expression in Mahoney atlas).
(Figs. 3A, 4). However, these data do not address the role of Tcf4 itself in formation of myelin. As shown in Figure $7 B$, the spinal cords of Tcf 4 knock-out mice show little difference in the number of cells that express early markers of the oligodendrocyte lineage such as Olig2 or platelet-derived growth factor receptor $\alpha$ $(\mathrm{PDGFR} \alpha)$ when examined at P0. Thus, Tcf4 is dispensable for the initial specification of oligodendrocyte progenitors (see schematic in Fig. 6A). However, as shown in Figure $7 A$, there are significant differences in expression of later markers for oligoden- 
drocytes. For example, CNPase is almost nonexistent in Tcf4 knock-out mice at P0. Moreover, the mRNA levels of the late marker proteins MBP and proteolipid protein (PLP) are decreased to approximately one-third the levels in Tcf4 knock-out mice relative to their wild-type littermates at $\mathrm{P} 0$. Thus, Tcf4 promotes the maturation of oligodendrocyte progenitors, a function also ascribed to the bHLH transcription factor Olig1 (Arnett et al., 2004; Xin et al., 2005).

One important remaining question is whether Tcf4 expression must be extinguished before full maturation of oligodendrocytes. Unfortunately, Tcf4 knock-out mice die immediately after birth. Because spinal cord explant cultures are not technically feasible for postnatal stages and oligodendrocyte cultures are difficult to transfect and mature in vitro, additional biological tools, including the development of inducible Tcf 4 overexpression mouse models, will be required to fully define the role of Tcf 4 in development and repair of CNS white matter.

\section{Tcf4 probably functions as a \\ transcription activator in oligodendrocyte progenitors}

As a downstream effector of the Wnt signaling axis, Tcf4 can function as either a repressor or an activator of gene expression depending on the activation state of $\beta$-catenin (Clevers, 2006). In the absence of Wnt signaling, $\beta$-catenin is phosphorylated by the serine/threonine kinase GSK3 and rapidly proteolysed in the cell cytosol. Under these conditions, Tcf4 is a transcription repressor. In the presence of Wnt signaling, GSK3 function is silenced and the stabilized $\beta$-catenin moves into the cell nucleus. Under these conditions, Tcf4 is a transcription activator.

To obtain insight into the molecular mechanism whereby Tcf4 promotes the timely maturation of oligodendrocyte progenitors (Fig. 7A), we conducted double immunostaining with antibodies to Tcf 4 and $\beta$-catenin. As shown in Figure 8, all of the Tcf4-positive cells in the P5 spinal cord and also in our mixed glial cultures show $\beta$-catenin within their nuclei. Accordingly, Tcf4 probably functions as a transcription activator during the process of oligodendrocyte maturation.

\section{Discussion}

Transcription factors that specify formation of glia in genetically accessible organisms such as Drosophila and nematode worms have been essentially displaced and reassigned to different functions in vertebrate animals (Wegner and Riethmacher, 2001). For vertebrate CNS development, a short list of gliogenic transcription factors have been identified via spatially
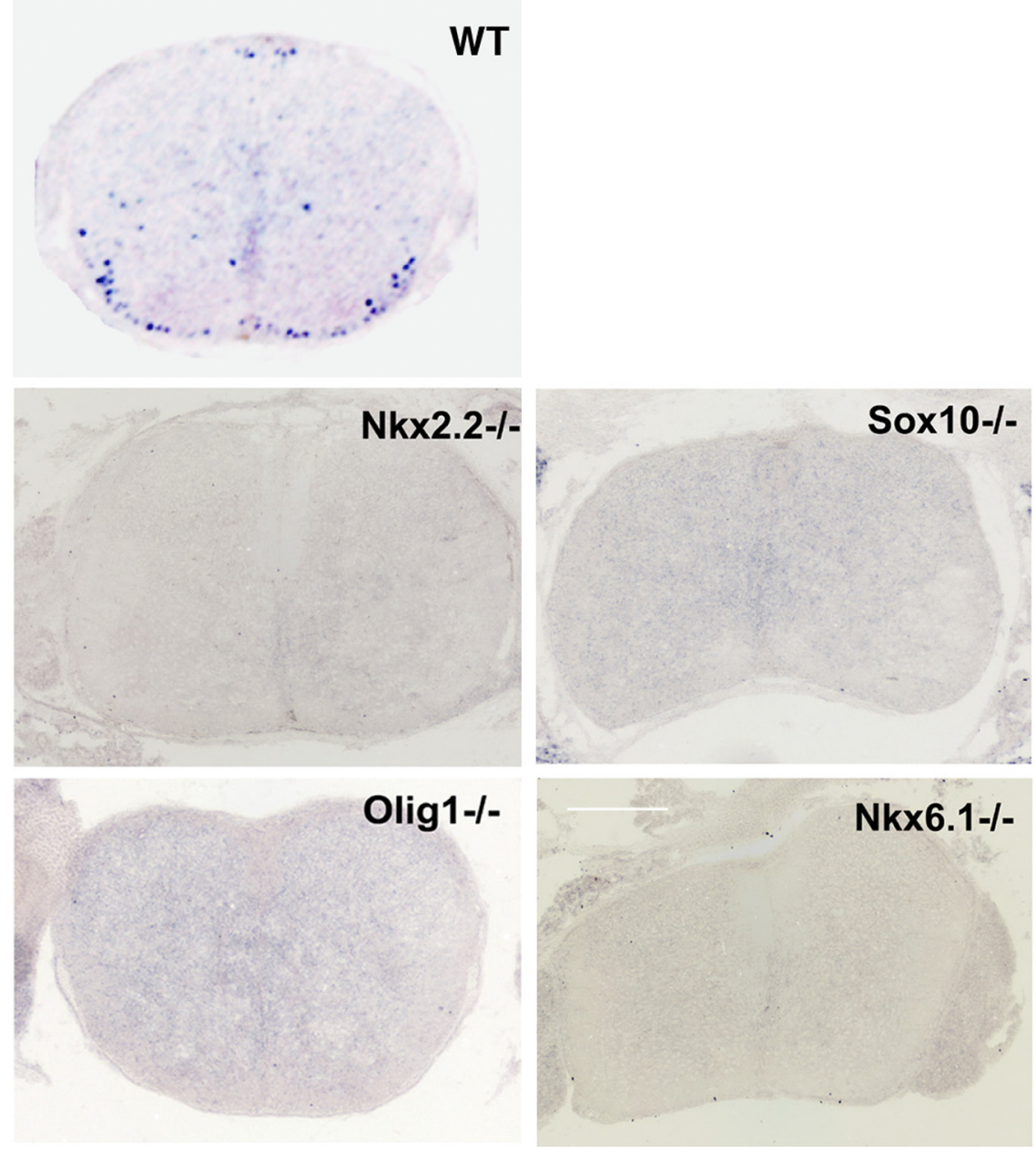

Figure 4. Tcf4 expression is ablated or attenuated in multiple hypomyelination mouse models. All of the in situ images shown are from E18.5 spinal cords. WT, Wild type. Scale bar, $100 \mu \mathrm{m}$.
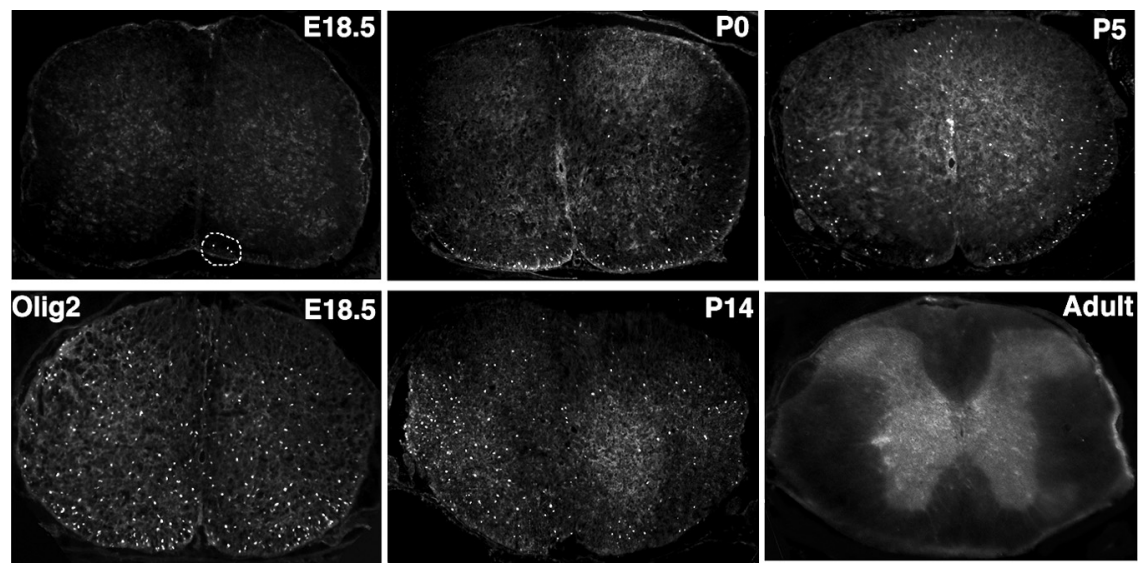

Figure 5. Temporal expression of Tff4 in developing spinal cord. In timed mating experiments, Tcf4 protein is barely detectable before E18.5 in the spinal cord (3 positive cells are circled). For comparative purpose, the expression pattern of Olig2 in E18.5 mouse spinal cord is shown below the Tcf4 image. Between P0 and P14, Tcf4 protein is readily detectable. In mature white matter of the adult spinal cord, however, Tcf4 is no longer expressed.

restricted expression patterns in developing spinal cord, including Olig1, Olig2, Scl, Sox 9, Sox10, Nfia, and Nfib (Lu et al., 2000; Zhou et al., 2000; Stolt et al., 2002, 2003; Muroyama et al., 2005; Deneen et al., 2006). We show here how a visual database can be used to expand on this gene discovery strategy. 


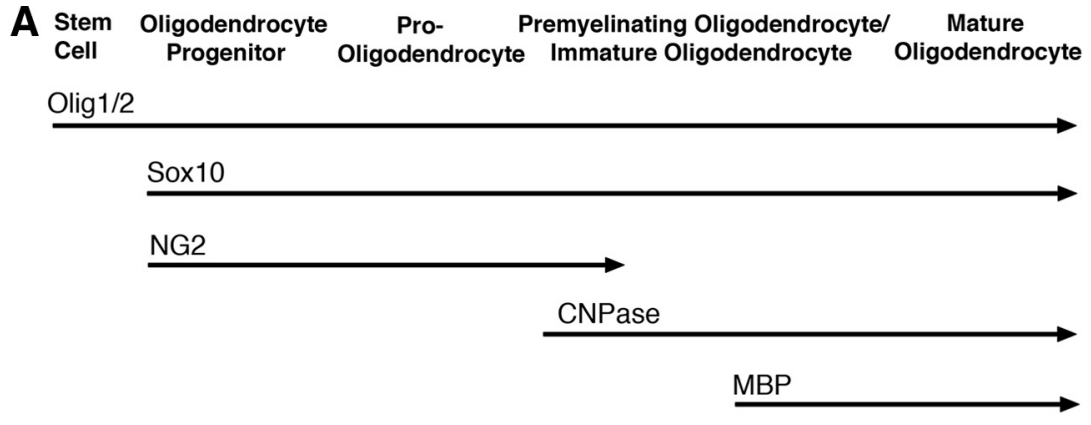

B
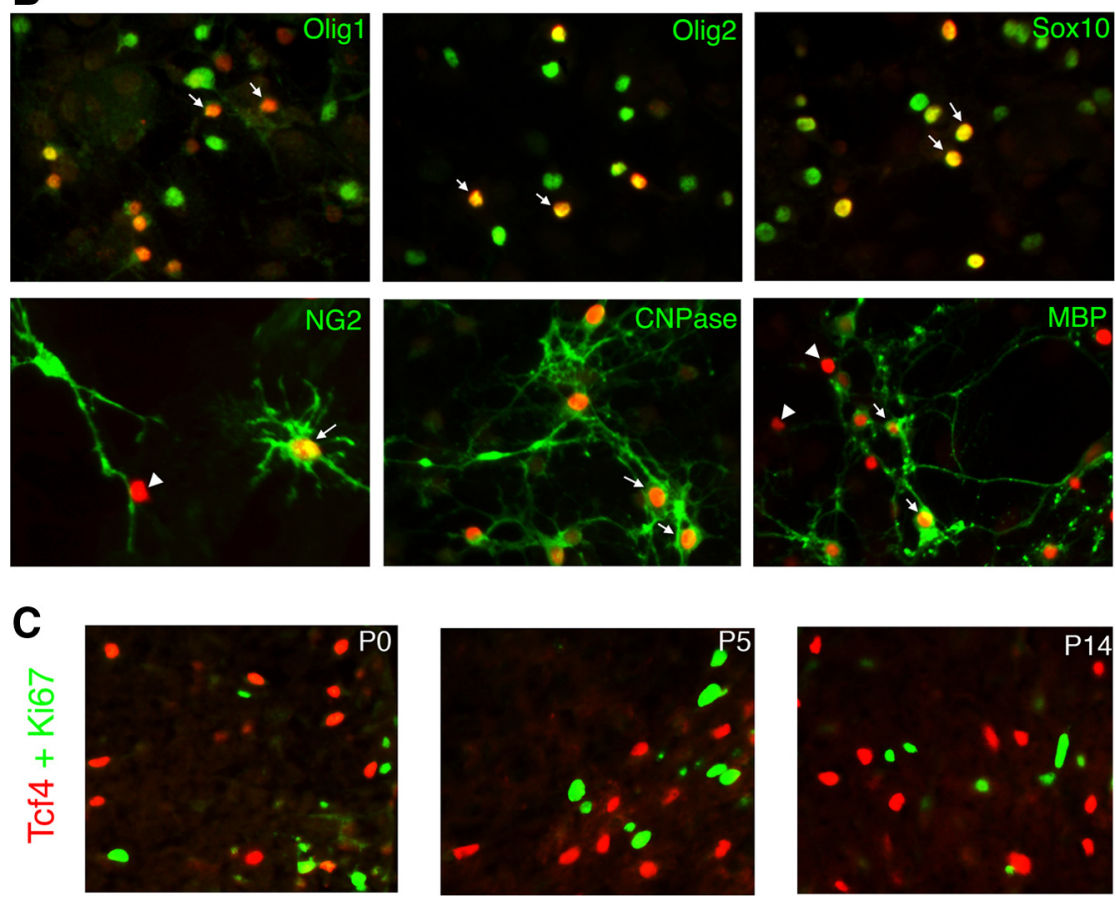

Figure 6. Tcf4 marks postmitotic/premyelinating oligodendrocytes. $A$, Schematic drawing of stage-specific markers for oligodendrocyte development. $\boldsymbol{B}$, Double immunofluorescence of $\mathrm{Tff}$ (red) with stage-specific markers (green) in mixed glia cultures Arrows point to the double-labeled cells, and arrowheads point to cells that are only Tcf4 ${ }^{+}$. As expected, $\mathrm{Tcf} 4$ is expressed in a subpopulation of 0 lig1 ${ }^{+}$, Olig2 ${ }^{+}$, and Sox $10^{+}$cells because these markers are detectable at all stages of oligodendrocyte formation $[36 \pm 11 \%(n=9), 40 \pm 12 \%(n=3)$, and $35 \pm 8 \%(n=7)$, respectively]. However, Tcf4 shows a near $90 \%$ overlap with CNPase $[88 \pm 2 \%(n=9)]$ and only partial overlap with NG2 [47 $\pm 20 \%(n=6)]$ or MBP $[36 \pm 12 \%(n=5)]$. C, Double immunofluorescence with antibodies to Tff4 (red) and Ki67 (green), a marker for dividing cells. As indicated, there is no overlap between Tcf4 and Ki67.

From an entry-level list of $>1400$ candidates, we identified 87 transcription factors that are expressed at early times in the germinal zone of the developing spinal cord. From this spatially restricted cohort of 87 candidates, we identified a subset of 12 novel transcription factors that (1) show sustained expression in spinal cord white matter and (2) have not hitherto been linked to glial development. Both of the gene sets contain chromatin remodeling proteins and regulators of cell division. More detailed studies of those genes could lead to a greater understanding of chromatin modification during glial development and possibly the molecular mechanisms coupling cell division with cell differentiation. Knock-out mice for many of the 12 novel genes exist. Most of them can be categorized into two groups, embryonic lethal and those with little or no phenotype in the CNS. The former genes will require conditional knock-out strategies, whereas the latter may benefit from combinatorial knock-outs.
One caveat to an entry-level screen based on in situ expression data is that the presence of mRNA does not always equate to the expression of protein. Tcf 4 mRNA, for example, is seen in oligodendrocyte progenitors as early as E13.5 by in situ hybridization. However, Tcf4 protein, as detected by immunostaining, is not seen until E18.5. In contradistinction, Tcf4 mRNA expression in neurons correlates well with expression of the protein (data not shown). We and others have noted a similar disconnect in Olig1, which has been linked to maturation of oligodendrocyte progenitors. Expression of Olig1 mRNA can be seen at times as early as E9 in developing spinal cord (Lu et al., 2000). However, multiple different antibody preparations fail to detect Olig1 protein until E18.5 when oligodendrocyte progenitors have begun to mature (J. A. Alberta and C. D. Stiles, unpublished observations). It seems likely that the function of these transcription factors is regulated in part by posttranscriptional mechanisms. Sequence analysis of Olig1 and Tcf 4 mRNA transcripts reveals multiple potential binding sites for microRNAs (MiRBase, http://microrna.sanger.ac.uk).

From a cluster of novel transcription factors with an oligodendrocyte-like expression pattern (Fig. 2), Tcf4 was chosen for functional analysis in part because of its known involvement in the Wnt signaling pathway (Kühl et al., 2000). A broad body of literature documents Tcf4 functions in the development of intestinal stem cells as well as in colorectal tumor formation (Korinek et al., 1997, 1998; Morin et al., 1997). More recently, a strong link between Tcf4 and type 2 diabetes has been described (Grant et al., 2006). Tcf4 expression in the developing CNS, however, correlates strongly with oligodendrocyte maturation. Relative to their wild-type littermates, Tcf4 knock-out mice express much less CNPase protein and MBP and PLP mRNA at P0 (Fig. 7). Moreover, Tcf4 expression is attenuated in several different hypomyelination models (Figs. 3, 4). Preliminary results culturing Tcf 4 knock-out cells suggest that oligodendrocyte progenitors are present in similar numbers but show a developmental delay in maturation that mimics the in vivo situation. It is unclear whether these cells would eventually catch up to their wild-type counterparts. In other studies, we have seen that Tcf4 is upregulated during the remyelination stage in the cuprizone model of relapsing/remitting multiple sclerosis (data not shown), further suggesting that Tcf4 plays a role in oligodendrocyte maturation. However, in silico analysis of the $10 \mathrm{~kb}$ upstream promoter regions of CNPase, MBP, and PLP genes failed to discover any Tcf4 binding sites.

He et al. (2007) have shown that targeted disruption of the Ying Yang 1 (YY1) transcription factor leads to overexpression of Tcf4 and an accumulation of immature oligodendrocytes. 
This YY1 knock-out phenotype would be predicted from our own observations that Tcf4 is expressed in premyelinating oligodendrocyte progenitors but not in mature oligodendrocytes. He et al. also showed that ectopic Tcf4 suppresses the expression of myelin reporter constructs. However, it is well known that Tcf4 by itself is a transcription inhibitor. Coexpression with activated $\beta$-catenin is required to convert Tcf4 into a transcription activator (Clevers and van de Wetering, 1997). We find that all Tcf4-positive spinal cord cells express $\beta$-catenin in their nuclei, suggesting that Wnt signaling is important for this stage of oligodendrocyte differentiation (Fig. 8). Our results appear to contradict previous reports suggesting that Wnt signaling prevents oligodendrocyte differentiation (Shimizu et al., 2005; Kim et al., 2008). However, both studies address the role of Wnt signaling during the window of oligodendrocyte specification and/or proliferation, a time before Tcf4 protein expression. Furthermore, the pharmacological activation of Wnt signaling resulted in increased apoptosis and few surviving oligodendrocytes, making it difficult to interpret the role of Wnt signaling on differentiation. While this manuscript was under review, Fancy et al. (2009) published a survey of transcription factors involved in the repair of demyelinated lesions in the postnatal CNS, and Ye et al. (2009) characterized the role of Wnt pathway signaling in oligodendrocyte development. Both of these studies converged on Tcf4 as a central component of oligodendrocyte progenitor maturation, thus providing independent support of the conclusions drawn here.

To this point, there are only a few examples of transcription factors that have been shown to be both necessary and sufficient for the genesis of vertebrate astrocytes. The Sox 9 and Nfia/b gene products appear to play broad roles in astrocyte development. However, Sox 9 and Nfia/b are both expressed in oligodendrocytes as well as astrocytes, and the formation of these two cell types is mutually exclusive. For example, bone morphogenic proteins promote astrocytes and inhibit oligodendrocytes (Gross et al., 1996; Mekki-Dauriac et al., 2002; Gomes et al., 2003), whereas Olig2 promotes formation of oligodendrocytes and inhibits formation of astrocytes (Zhou and Anderson, 2002; Fukuda et al., 2004; Setoguchi and Kondo, 2004). Accordingly, the pivotal functions of Sox9 and Nfia/b in formation of astrocytes may be to inhibit neuronal fate choice, making the resulting cells permissive for glial development.
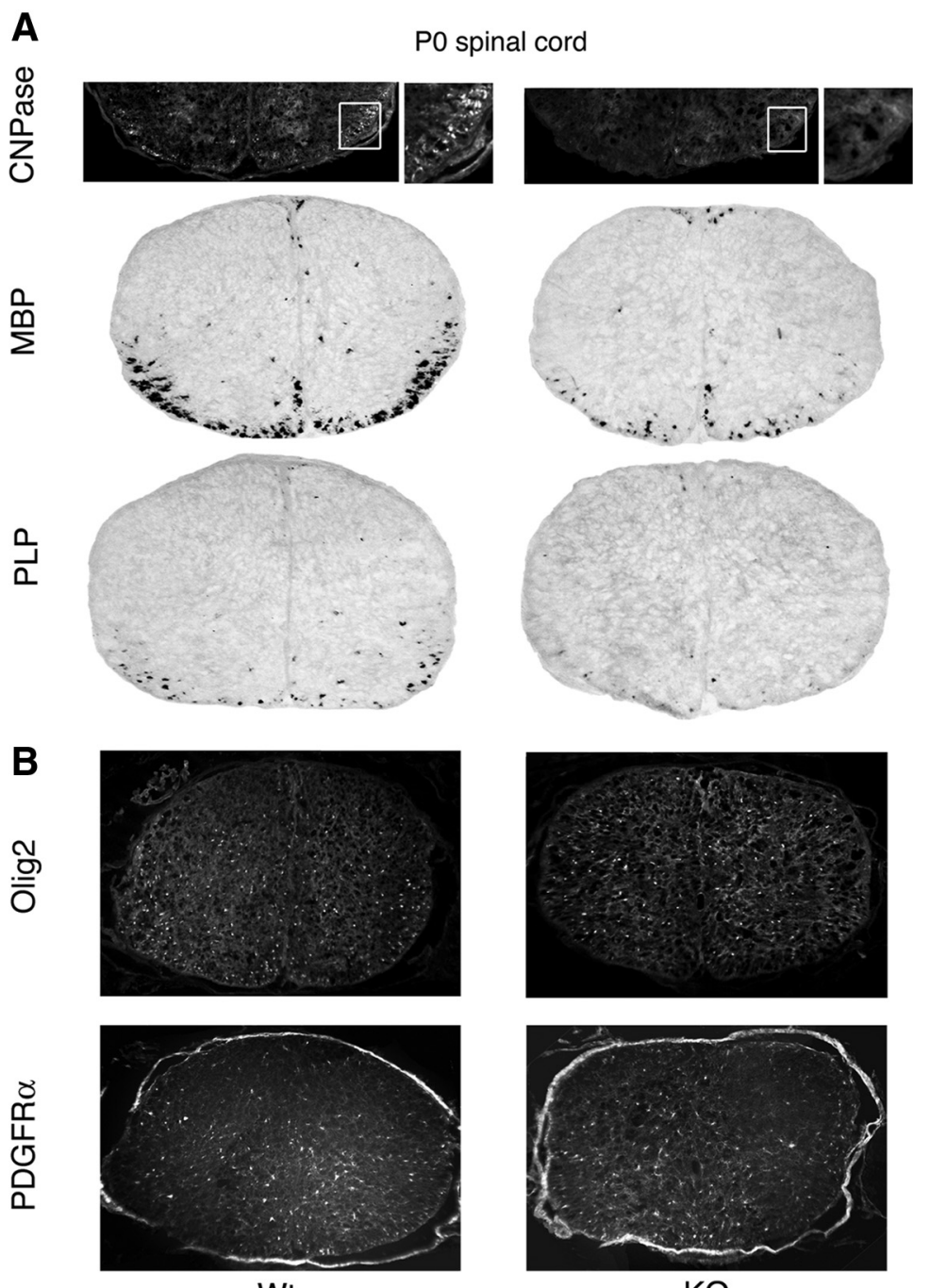

$\mathrm{KO}$

Figure 7. Tcf4 expression is required for maturation of oligodendrocyte progenitors but is dispensable for their initial specification. $A, A t P 0$, expression of late markers of the oligodendrocyte lineage (CNPase, MBP, and PLP) is reduced or delayed in the Tcf4 knock-out mice relative to wild-type littermates [MBP: knock-out, $29 \pm 3 \%(n=3)]$. CNPase is detected by immunofluorescence with insets (white boxes) shown at higher magnification. MBP and PLP are detected by in situ hybridization. $\boldsymbol{B}$, In contrast to late markers, early markers of the oligodendrocyte lineage ( 0 lig2 and PDGFR $\alpha$ ) are unaffected by Tcf4 knock-out at PO. Wt, Wild type; KO, knock-out.

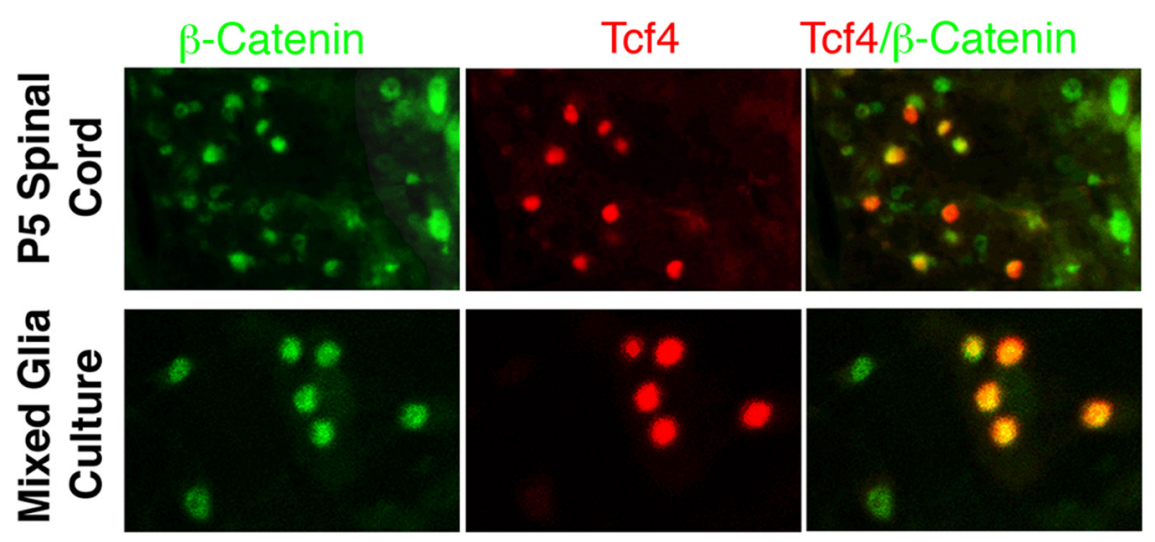

Figure 8. Tcf4 probably functions as a transcription activator in oligodendrocyte progenitors. Double immunofluorescence with antibodies to Tcf4 (red) and $\beta$-catenin (green) shows that Tcf4 is coexpressed with nuclear $\beta$-catenin in both P5 spinal cord white matter (top row) and mixed glia cell cultures (bottom row). Thus, Tcf4 is most likely functioning as a transcription activator in these cells. For details, see Results. 
We identified three novel transcription factors that meet our criteria for being astrocyte specific. Klf15 is biologically active in a spinal cord explant assay for the formation of ectopic astrocytes and is expressed in astrocytes of the postnatal spinal cord (Fig. 3). We note, in addition, that recent work in the Barres laboratory has identified Klf15 as one of the best candidates for an astrocytespecific transcription factor using expression array data obtained from highly purified astrocytes (Cahoy et al., 2008).

Overexpression of Klf15 in spinal cord explants leads to overexpression of GFAP. Loss-of-function studies with Klf15 (data not shown) were uninformative. The Klf15 knock-out mice are viable and fertile with no outward signs of a CNS defect such as tremor, seizure, or ataxia (Fisch et al., 2007; Gray et al., 2007). Klf15 knock-out mice show no differences in glial marker expression (GFAP, glutamate-aspartate transporter, glutamate synthase, and S-100 $\beta$ ) from wild-type littermates between E13.5 and $\mathrm{P} 14$, the critical stages in the development of astrocytes (data not shown). Klf15 is a member of the Kruppel-like family (Klf) of transcription factors, which play functional roles in cell growth and differentiation in a wide range of mammalian cell types (Black et al., 2001; Pearson et al., 2008). It is thus possible that other members of the Klf family are functionally redundant with Klf15 in the specification, maturation, or survival of astrocytes in the vertebrate CNS.

Several pictorial atlases of gene expression in the vertebrate CNS have appeared in recent years (Gong et al., 2003; Gray et al., 2004; Visel et al., 2004; Christiansen et al., 2006; Magdaleno et al., 2006; Lein et al., 2007). The content of these newer databases transcends transcription factors to include a wide range regulatory gene classes. Expression screens of these datasets along lines described here might identify novel growth factors, morphogenic proteins, cell surface receptors, and cytoplasmic signal generating proteins involved in the genesis of glial cells. In the fullness of time, identification of the agents that regulate glial development could have practical overtones for the therapy of a wide range of neurological disease states, including multiple sclerosis, hypoxic injury, and seizure disorders.

\section{References}

Arnett HA, Fancy SP, Alberta JA, Zhao C, Plant SR, Kaing S, Raine CS, Rowitch DH, Franklin RJ, Stiles CD (2004) bHLH transcription factor Olig1 is required to repair demyelinated lesions in the CNS. Science 306:2111-2115.

Barradas PC, Gomes SS, Cavalcante LA (1995) CNPase expression in the developing opossum brain stem and cerebellum. Neuroreport 6:289-292.

Black AR, Black JD, Azizkhan-Clifford J (2001) Spl and kruppel-like factor family of transcription factors in cell growth regulation and cancer. J Cell Physiol 188:143-160.

Cahoy JD, Emery B, Kaushal A, Foo LC, Zamanian JL, Christopherson KS, Xing Y, Lubischer JL, Krieg PA, Krupenko SA, Thompson WJ, Barres BA (2008) A transcriptome database for astrocytes, neurons, and oligodendrocytes: a new resource for understanding brain development and function. J Neurosci 28:264-278.

Christiansen JH, Yang Y, Venkataraman S, Richardson L, Stevenson P, Burton N, Baldock RA, Davidson DR (2006) EMAGE: a spatial database of gene expression patterns during mouse embryo development. Nucleic Acids Res 34:D637-D641.

Clevers H (2006) Wnt/beta-catenin signaling in development and disease. Cell 127:469-480.

Clevers H, van de Wetering M (1997) TCF/LEF factor earn their wings. Trends Genet 13:485-489.

Deneen B, Ho R, Lukaszewicz A, Hochstim CJ, Gronostajski RM, Anderson DJ (2006) The transcription factor NFIA controls the onset of gliogenesis in the developing spinal cord. Neuron 52:953-968.

Fancy SP, Baranzini SE, Zhao C, Yuk DI, Irvine KA, Kaing S, Sanai N, Franklin RJ, Rowitch DH (2009) Dysregulation of the Wnt pathway inhibits timely myelination and remyelination in the mammalian CNS. Genes Dev 23:1571-1585.

Fisch S, Gray S, Heymans S, Haldar SM, Wang B, Pfister O, Cui L, Kumar A, Lin Z, Sen-Banerjee S, Das H, Petersen CA, Mende U, Burleigh BA, Zhu Y, Pinto YM, Pinto Y, Liao R, Jain MK (2007) Kruppel-like factor 15 is a regulator of cardiomyocyte hypertrophy. Proc Natl Acad Sci U S A 104:7074-7079.

Fu H, Qi Y, Tan M, Cai J, Takebayashi H, Nakafuku M, Richardson W, Qiu M (2002) Dual origin of spinal oligodendrocyte progenitors and evidence for the cooperative role of Olig2 and Nkx2.2 in the control of oligodendrocyte differentiation. Development 129:681-693.

Fukuda S, Kondo T, Takebayashi H, Taga T (2004) Negative regulatory effect of an oligodendrocytic bHLH factor OLIG2 on the astrocytic differentiation pathway. Cell Death Differ 11:196-202.

Gomes WA, Mehler MF, Kessler JA (2003) Transgenic overexpression of BMP4 increases astroglial and decreases oligodendroglial lineage commitment. Dev Biol 255:164-177.

Gong S, Zheng C, Doughty ML, Losos K, Didkovsky N, Schambra UB, Nowak NJ, Joyner A, Leblanc G, Hatten ME, Heintz N (2003) A gene expression atlas of the central nervous system based on bacterial artificial chromosomes. Nature 425:917-925.

Grant SF, Thorleifsson G, Reynisdottir I, Benediktsson R, Manolescu A, Sainz J, Helgason A, Stefansson H, Emilsson V, Helgadottir A, Styrkarsdottir U, Magnusson KP, Walters GB, Palsdottir E, Jonsdottir T, Gudmundsdottir T, Gylfason A, Saemundsdottir J, Wilensky RL, Reilly MP, et al. (2006) Variant of transcription factor 7-like 2 (TCF7L2) gene confers risk of type 2 diabetes. Nat Genet 38:320-323.

Gray PA, Fu H, Luo P, Zhao Q, Yu J, Ferrari A, Tenzen T, Yuk DI, Tsung EF, Cai Z, Alberta JA, Cheng LP, Liu Y, Stenman JM, Valerius MT, Billings N, Kim HA, Greenberg ME, McMahon AP, Rowitch DH, et al. (2004) Mouse brain organization revealed through direct genome-scale TF expression analysis. Science 306:2255-2257.

Gray S, Wang B, Orihuela Y, Hong EG, Fisch S, Haldar S, Cline GW, Kim JK, Peroni OD, Kahn BB, Jain MK (2007) Regulation of gluconeogenesis by Kruppel-like factor 15. Cell Metab 5:305-312.

Gross RE, Mehler MF, Mabie PC, Zang Z, Santschi L, Kessler JA (1996) Bone morphogenetic proteins promote astroglial lineage commitment by mammalian subventricular zone progenitor cells. Neuron 17:595-606.

He Y, Dupree J, Wang J, Sandoval J, Li J, Liu H, Shi Y, Nave KA, CasacciaBonnefil P (2007) The transcription factor Yin Yang 1 is essential for oligodendrocyte progenitor differentiation. Neuron 55:217-230.

Kim S, Kim SH, Kim H, Chung AY, Cha YI, Kim CH, Huh TL, Park HC (2008) Frizzled 8a function is required for oligodendrocyte development in the zebrafish spinal cord. Dev Dyn 237:3324-3331.

Korinek V, Barker N, Morin PJ, van Wichen D, de Weger R, Kinzler KW, Vogelstein B, Clevers H (1997) Constitutive transcriptional activation by a beta-catenin-Tcf complex in APC $-/-$ colon carcinoma. Science 275:1784-1787.

Korinek V, Barker N, Moerer P, van Donselaar E, Huls G, Peters PJ, Clevers H (1998) Depletion of epithelial stem-cell compartments in the small intestine of mice lacking Tcf-4. Nat Genet 19:379-383.

Kühl M, Sheldahl LC, Park M, Miller JR, Moon RT (2000) The Wnt/Ca2+ pathway: a new vertebrate Wnt signaling pathway takes shape. Trends Genet 16:279-283.

Lein ES, Hawrylycz MJ, Ao N, Ayres M, Bensinger A, Bernard A, Boe AF, Boguski MS, Brockway KS, Byrnes EJ, Chen L, Chen L, Chen TM, Chin MC, Chong J, Crook BE, Czaplinska A, Dang CN, Datta S, Dee NR, et al. (2007) Genome-wide atlas of gene expression in the adult mouse brain. Nature 445:168-176.

Liu R, Cai J, Hu X, Tan M, Qi Y, German M, Rubenstein J, Sander M, Qiu M (2003) Region-specific and stage-dependent regulation of Olig gene expression and oligodendrogenesis by Nkx6.1 homeodomain transcription factor. Development 130:6221-6231.

Lu QR, Yuk D, Alberta JA, Zhu Z, Pawlitzky I, Chan J, McMahon AP, Stiles CD, Rowitch DH (2000) Sonic hedgehog-regulated oligodendrocyte lineage genes encoding bHLH proteins in the mammalian central nervous system. Neuron 25:317-329.

Lu QR, Sun T, Zhu Z, Ma N, Garcia M, Stiles CD, Rowitch DH (2002) Common developmental requirement for Olig function indicates a motor neuron/oligodendrocyte connection. Cell 109:75-86.

Magdaleno S, Jensen P, Brumwell CL, Seal A, Lehman K, Asbury A, Cheung T, Cornelius T, Batten DM, Eden C, Norland SM, Rice DS, Dosooye N, 
Shakya S, Mehta P, Curran T (2006) BGEM: an in situ hybridization database of gene expression in the embryonic and adult mouse nervous system. PLoS Biol 4:e86.

Matys V, Fricke E, Geffers R, Gössling E, Haubrock M, Hehl R, Hornischer K, Karas D, Kel AE, Kel-Margoulis OV, Kloos DU, Land S, Lewicki-Potapov B, Michael H, Münch R, Reuter I, Rotert S, Saxel H, Scheer M, Thiele S, Wingender E, et al. (2003) TRANSFAC: transcriptional regulation, from patterns to profiles. Nucleic Acids Res 31:374-378.

McCarthy KD, de Vellis J (1980) Preparation of separate astroglial and oligodendroglial cell cultures from rat cerebral tissue. J Cell Biol 85:890 -902.

Mekki-Dauriac S, Agius E, Kan P, Cochard P (2002) Bone morphogenetic proteins negatively control oligodendrocyte precursor specification in the chick spinal cord. Development 129:5117-5130.

Morin PJ, Sparks AB, Korinek V, Barker N, Clevers H, Vogelstein B, Kinzler KW (1997) Activation of beta-catenin-Tcf signaling in colon cancer by mutations in beta-catenin or APC. Science 275:1787-1790.

Muroyama Y, Fujiwara Y, Orkin SH, Rowitch DH (2005) Specification of astrocytes by bHLH protein SCL in a restricted region of the neural tube. Nature 438:360-363.

Pearson R, Fleetwood J, Eaton S, Crossley M, Bao S (2008) Kruppel-like transcription factors: a functional family. Int J Biochem Cell Biol 40:1996-2001.

Privat A, Rataboul P (1986) Fibrous and protoplasmic astrocytes. In: Astrocytes: development, morphology and regional specialization of astrocytes (Fedoroff S, Vernadakis A, eds), pp 105-130. Orlando: Academic.

Qi Y, Cai J, Wu Y, Wu R, Lee J, Fu H, Rao M, Sussel L, Rubenstein J, Qiu M (2001) Control of oligodendrocyte differentiation by the Nkx2.2 homeodomain transcription factor. Development 128:2723-2733.

Setoguchi T, Kondo T (2004) Nuclear export of OLIG2 in neural stem cells is essential for ciliary neurotrophic factor-induced astrocyte differentiation. J Cell Biol 166:963-968.

Shimizu T, Kagawa T, Wada T, Muroyama Y, Takada S, Ikenaka K (2005) Wnt signaling controls the timing of oligodendrocyte development in the spinal cord. Dev Biol 282:397-410.

Sonnhammer EL, Eddy SR, Birney E, Bateman A, Durbin R (1998) Pfam: multiple sequence alignments and HMM-profiles of protein domains. Nucleic Acids Res 26:320-322.

Stolt CC, Rehberg S, Ader M, Lommes P, Riethmacher D, Schachner M, Bartsch U, Wegner M (2002) Terminal differentiation of myelinforming oligodendrocytes depends on the transcription factor Sox10. Genes Dev 16:165-170.
Stolt CC, Lommes P, Sock E, Chaboissier MC, Schedl A, Wegner M (2003) The Sox 9 transcription factor determines glial fate choice in the developing spinal cord. Genes Dev 17:1677-1689.

Takebayashi H, Yoshida S, Sugimori M, Kosako H, Kominami R, Nakafuku M, Nabeshima Y (2000) Dynamic expression of basic helix-loop-helix Olig family members: implication of Olig2 in neuron and oligodendrocyte differentiation and identification of a new member, Olig3. Mech Dev 99:143-148.

Takebayashi H, Nabeshima Y, Yoshida S, Chisaka O, Ikenaka K, Nabeshima Y (2002) The basic helix-loop-helix factor olig2 is essential for the development of motoneuron and oligodendrocyte lineages. Curr Biol 12:1157-1163.

Thomas PD, Campbell MJ, Kejariwal A, Mi H, Karlak B, Daverman R, Diemer K, Muruganujan A, Narechania A (2003) PANTHER: a library of protein families and subfamilies indexed by function. Genome Res 13:2129-2141.

Visel A, Thaller C, Eichele G (2004) GenePaint.org: an atlas of gene expression patterns in the mouse embryo. Nucleic Acids Res 32:D552-D556.

Wegner M, Riethmacher D (2001) Chronicles of a switch hunt: gcm genes in development. Trends Genet 17:286-290.

Wheeler DL, Church DM, Edgar R, Federhen S, Helmberg W, Madden TL, Pontius JU, Schuler GD, Schriml LM, Sequeira E, Suzek TO, Tatusova TA, Wagner L (2004) Database resources of the National Center for Biotechnology Information: update. Nucleic Acids Res 32:D35-D40.

Xin M, Yue T, Ma Z, Wu FF, Gow A, Lu QR (2005) Myelinogenesis and axonal recognition by oligodendrocytes in brain are uncoupled in Olig1null mice. J Neurosci 25:1354-1365.

Ye F, Chen Y, Hoang T, Montgomery RL, Zhao XH, Bu H, Hu T, Taketo MM, van Es JH, Clevers H, Hsieh J, Bassel-Duby R, Olson EN, Lu QR (2009) $\mathrm{HDAC} 1$ and HDAC2 regulate oligodendrocyte differentiation by disrupting the beta-catenin-TCF interaction. Nat Neurosci 12:829-838.

Zhou Q, Anderson DJ (2002) The bHLH transcription factors OLIG2 and OLIG1 couple neuronal and glial subtype specification. Cell 109:61-73.

Zhou Q, Wang S, Anderson DJ (2000) Identification of a novel family of oligodendrocyte lineage-specific basic helix-loop-helix transcription factors. Neuron 25:331-343.

Zhou Q, Choi G, Anderson DJ (2001) The bHLH transcription factor Olig2 promotes oligodendrocyte differentiation in collaboration with $\mathrm{Nkx} 2.2$. Neuron 31:791-807. 